\title{
Defining Narration
}

\begin{abstract}
This chapter concisely demarcates narration within the broad field of communication. The story, which should be understood as the scaffolding core of a narrative, is circumscribed as represented events that are temporally interrelated in a meaningful way. This definition is precise enough to be operable, yet general enough to work transmedially. After specifying a number of vital implications of the definition, these implications are elaborated in the context of some concepts in semiotics and cognitive science.
\end{abstract}

Keywords Transmedial narration $\bullet$ Narrative: Story $\bullet$ Represented events $\bullet$ Cognitive schemata $\bullet$ Collateral experience

Having outlined a general conceptual framework in the previous chapter, we are now in a position to drill down to the issue of demarcating narration within the broad field of communication. In this chapter I will suggest how narration can be circumscribed more precisely. Building on earlier research, I will first seek to formulate as precise definitions as possible of the concepts that are required to shape a transmedial understanding of narration. I will then elaborate on these defined concepts through an interrogation of some vital semiotic and cognitive ideas. Thus, the chapter will first narrow down the perspective, only to broaden it again. 


\section{Transmedial Delineations}

Almost all definitions of narration and narratives in the literature are clearly related to each other. On the whole, then, there is little serious disagreement about how the central concept denoted by terms such as 'narration' and 'narrative' should be understood. The disagreements are to be found in those important details that make it possible to operationalize the concept in various ways. Those particulars are often more or less media-specific and hence, from a transmedial perspective, too peripheral to fit into a precise definition. Here, I will illustrate with a handful of succinct definitions from research on various media areas.

Writing about spoken language, William Labov specified a narrative as "a verbal sequence of clauses" that represents events: "we can define a minimal narrative as a sequence of two clauses which are temporally ordered", meaning that the represented events must contain at least one "temporal juncture" (Labov 1972: 359-361). The most media-specific elements here are clearly "verbal" and "clauses". Discarding them, the idea of at least two represented events that are temporally ordered remains. Working mainly with literature, Gerald Prince's most schematic description of a narrative says that it "may be defined as the representation of real or fictive events and situations in a time sequence" (Prince 1982: 1). This is already a functioning transmedial definition, although the notion of situation is perhaps not transmedially ideal. As will be demonstrated in Chap. 9, I also find the distinction between "real or fictive events" to be much too crude to be useful. Vincent Meelberg, who mainly works with music but with a pronounced transmedial approach, defined a narrative as "the representation of a succession of events that succeed each other in time" (Meelberg 2006: 39). This is also a fully functioning transmedial definition, although, on closer inspection, Meelberg's idea of representation turns out to be much too narrow as it excludes several media types from the realm of representation. Finally, Murray Smith, who also approached the matter transmedially, first suggested that "A narrative is constituted by a set of agents and events linked in a cause-effect fashion" (Smith 2009: 2). After some discussion about uncertainties, he excluded the concept of agents and stated that "Perhaps the most minimal definition would stipulate only that, in a narrative, events must be represented in time" (Smith 2009: 3).

I have no objections to such a conclusion, although naturally everything depends on exactly how one understands the concepts of representa- 
tion, events, and temporal relations-and on how one frames these entities. My way of explicating narration is to conceptualize it in terms of communication and media products - the intermediate entities of communication among minds-and how one construes cognitive import on the basis of media products. I have already stated that narratives are virtual spheres with certain features, and this statement can now be qualified by adding exactly the indispensable features that we have recently approached: narratives are virtual spheres containing events that are represented in time. This means that the events are represented in such a way that they are understood to occur at different points of time within the virtual sphere, whether these moments are situated in the past, in the present, or in the future in relation to the creation of the representing media product. In line with much narratological research, I also argue that the events must be perceived to be meaningfully related-a notion that I prefer to keep rather open, given the multitude of cognitive operations available for us to make valid connections among things and phenomena.

I believe that these conditions are both specific enough to be practically useful and general enough to be broadly transmedial. Therefore, I propose defining a narrative as a virtual sphere, emerging in communication, containing events that are temporally related to each other in a meaningful way. Thus, the core of a narrative is exactly this: represented events that are temporally interrelated in a meaningful way. As the core consists of several elements, it might also be described as a scaffold. I also suggest that a whole virtual sphere containing such a core and normally also other media characteristics should be called a narrative and that the scaffolding core should be called a story. Narration should simply be understood as the communication of narratives.

From this, it follows that what we perceive to be the same story may be realized in dissimilar settings in different narratives. What we recognize as basically the same story can be narrated in different ways. For those acquainted with literature and film narratology, this conclusion does not come as a surprise. However, the nature of the sameness of stories has been debated, and here I prefer to take a pragmatic stance. I simply do not believe that there is a method of exactly delimiting the story of an actual narrative; virtual spheres are rather fragile mental constructs that cannot always be intersubjectively dissected. The philosophical difficulty of establishing whether stories in different narratives are "the same" or only belong to the same "story type" (Smuts 2009), for instance, is interesting but of little significance for understanding transmediality. I do not think 
that definitively establishing such issues is necessary or even possible outside the realm of copyright trials. While the complexity of actual cases of narration may be illuminated and partly disentangled with the aid of the theoretical distinction between narrative and story, there is not necessarily always a point in trying to establish exact borders. I would argue that boundaries between complete narratives and their scaffolding story cores might well be differently conceived depending on the perceiver's background knowledge and perspectives. What is crucial for transmedial research is that it is possible, common, and often useful to perceive that vital core constituents of some narratives-certain events being temporally related in certain ways-are more or less similar to vital core constituents of other narratives, possibly represented by other media types.

Given these conditions, it must also be emphasized that stories may either be construed for the first time by the perceivers of media products (on the basis of salient structures emerging as the narratives develop in the mind) or be recognized (from earlier encounters with narratives or events in the world). In other words, the story may be based either mainly on intracommunicational objects arising in the virtual sphere, or on extracommunicational objects in the form of already known stories or perceived events. In any case, stories have no autonomous existence, as one might be led to believe by certain narratological discussions. They are always results of some sort of interpretation performed by certain persons in particular communicative circumstances; never objective existences, but possibly intersubjectively construed (cf. Thon 2016).

The theoretical distinction between a complete narrative and its scaffolding core story is essential for understanding transmedial narration: stories are embedded in narratives and they may also, to a certain extent, be realized by dissimilar media. However, the surrounding narratives and the representing media products are often conflated in narrative theory and sometimes termed discourse (they are not conflated by Chatman, though; see 1978: 23-24). However, there are not only two levels here-called, for instance, story and discourse-but rather three (cf. Genette 1980 [1972] and Bal 2009 who also suggested three-layer distinctions, although quite different from mine; cf. also discussions of "three levels" in Meelberg 2006: 43-44; Thon 2016: 36). A full discussion of all suggested conceptualizations of the matter would lead me far off track, so here I will simply make clear some consequences of my conceptualization of narration so far, which leads us to recognizing these three levels. 
- A media product with particular basic media traits and other formative qualities provides certain sensory configurations that are perceived by someone; these sensory configurations come to represent

- ... media characteristics forming a complete narrative with all its many specific details and features; furthermore, the perceiver comprehends that this narrative surrounds ...

- ... a scaffolding core, the story, consisting of represented events that are temporally interrelated in a meaningful way.

It should also be reemphasized that stories and parts of their surroundings in the whole narrative may often be realized fairly completely by several kinds of media. This is because many media types have the capacity, to some extent, to represent events, temporal relationships, meaningful relationships, and an abundance of other media characteristics. The story is normally only one of many transmedial media characteristics in narratives. The complete narrative of a certain media product may include a multitude of different media characteristics that may be more or less transmedial. However, as a rule, a story, consisting of the essential temporal structure of a narrative, is more transmedial than the complete narrative, although probably never wholly transmedial (cf. rewarding discussions of this issue in Gaudreault and Marion 2004).

\section{Semiotic and Cognitive Elaborations}

Brief definitions such as those in the previous section cannot stand alone; they must be entrenched in more comprehensive frameworks. I have already introduced and developed the frame of communication and the idea that narratives consist of represented events. In Peircean semiotic terms, this means, more specifically, as we have noted, that they are made up of represented objects that are construed such that they result in interpretants making meaningfully interrelated events present to the mind of the perceiver. To push the exploration of transmedial narration forward at this point, I must reemphasize that objects do not arise out of nothing; they depend on what Peirce calls collateral experience.

In this context, collateral experience is understood as collateral experience in the extracommunicational domain: what the perceiver of media products already somehow knows of or is familiar with. It may be experi- 
ence of anything from simple entities such as water to complex processes such as how to build a house, or indeed knowledge of specific narratives. Collateral experience may also be understood as even more profound and omnipresent experiences, such as those emphasized by Mandler and Johnson: experience of common structures of perception and body activity. Their theories may be understood as suggesting explanations of pervasive cognitive processes that are also reflected in communication. Thus, the notion that virtual spheres are formed by extracommunicational objects, background knowledge, covers both inescapable, prevalent experiences, such as those emphasized by Mandler and Johnson, and more specific and individual experiences, such as memories of certain items and events in one's life.

Earlier narratological research has accurately highlighted the relevance of collateral experience in general and, more specifically, collateral experience of more or less essential parts of narratives. Emma Kafalenos has emphasized that the perceiver's background knowledge largely determines the construction of narratives (Kafalenos 1996). Marie-Laure Ryan has stressed the difference between narratives that, at one extreme are entirely "new to the receiver" and, at the other extreme, are utterly dependent upon "the receiver's previous knowledge" (Ryan 2004a: 14; cf. Groensteen 2013 [2011]: 25). In the same vein, Michael Ranta has argued that previous knowledge is indeed very important and, furthermore, that, in general, "pictorial media, when compared to verbal language, require recipients who are more active in the reconstruction of narratives" (Ranta 2013: 7).

As Peircean semiotics is preoccupied with fundamental cognitive capacities and functions that render meaning-making possible, I think it is well in agreement with modern cognitive science. The central concept of $\operatorname{cog}$ nitive schemata can be understood as fundamental forms of collateral experience. To the best of my knowledge, film scholar David Bordwell was the first to apply cognitive research to narrative theory. He highlighted the fundamental role of the perceiver of narratives and emphasized that narratives are constructs that are dependent not only on the perceived qualities of the media products but also on expectations and hypotheses. In brief, the realization of narratives relies on cognitive schemata in the goaldirected perceiver's mind (Bordwell 1985: 29-47; these ideas were developed in Branigan 1992: 13-32; and, with the main focus on literature, in Fludernik 1996 and Herman 2002: 85-113; narratives are also seen as 
cognitive constructs in the transmedial narratology developed in Ryan 2006).

Cognitive schemata can be understood as cognitive blueprints that are used to efficiently deal with and make sense of new input from the external world, including input from communication. One could say that they are based on condensed forms of collateral experience; large amounts of experience of the world, again including communication, that are abstracted and generalized into schemata. For instance, after having cooked food many times, or having observed someone who has, a person is likely to develop some sort of cognitive schema based on the expected main events: first, one collects the primary products, then they are prepared, then again they are possibly heated or combined in some way, after which the meal is served and eaten. As with all schemata, this one is not absolutely accurate for all cooking, but it captures much of the essence of much cooking-and may therefore create expectations about how to proceed when preparing a meal. It is also clear to see that cognitive schemata like this may serve as material for narratives.

As one might expect, there is no consensus among researchers concerning the exact nature and function of cognitive schemata. In this context, I find it vital to emphasize the great diversity of cognitive schemata. As already noted, we have a plenitude of forms of collateral experience. By the same token, cognitive schemata, being based on collateral experience, must be understood as existing in a great deal of different forms. Our minds develop small and large schemata. Whereas some of them are more temporary and fade away, others stay with us for years or our entire life. We have schemata that concern trivial things and schemata that are related to matters of life and death. Some schemata evolve out of experience of nature, others build on culture, and yet others on both. There are cognitive schemata that are based on experience of mental entities and processes (such as intentional action; see Bundgaard 2007) and there are schemata that have developed out of collateral experience of material entities and processes. Schemata may be highly subjective or more or less intersubjective. Intersubjective cognitive schemata clearly facilitate communication.

Thus, perceiving represented events that are temporally interrelated in a meaningful way in a narrative is a cognitive process that depends on collateral experience and, more specifically, on cognitive schemata. Sensing interrelations to be meaningful is at least partially a question of being able to relate them to things that one is already familiar with. 


\section{REFERENCES}

Bal, Mieke. 2009. Narratology: Introduction to the Theory of Narrative. 3rd ed. Toronto: University of Toronto Press.

Bordwell, David. 1985. Narration in the Fiction Film. London and New York: Routledge.

Branigan, Edward. 1992. Narrative Comprehension and Film. London and New York: Routledge.

Bundgaard, Peer F. 2007. The cognitive import of the narrative schema. Semiotica 165: 247-261.

Chatman, Seymour. 1978. Story and Discourse: Narrative Structure in Fiction and Film. Ithaca, NY and London: Cornell University Press.

Fludernik, Monika. 1996. Towards a 'Natural' Narratology. London and New York: Routledge.

Gaudreault, André, and Philippe Marion. 2004. Transécriture and narrative mediatics: The stakes of intermediality. In A Companion to Literature and Film, ed. Robert Stam and Alessandra Raengo, trans. Robert Stam, 58-70. Malden: Blackwell.

Genette, Gérard. 1980 [1972]. Narrative Discourse: An Essay in Method. Translated by Jane E. Lewin. Ithaca, NY: Cornell University Press.

Groensteen, Thierry. 2013 [2011]. Comics and Narration. Translated by Ann Miller. Jackson: University Press of Mississippi.

Herman, David. 2002. Story Logic: Problems and Possibilities of Narrative. Lincoln and London: University of Nebraska Press.

Kafalenos, Emma. 1996. Implications of narrative in painting and photography. New Novel Review 3: 53-64.

Labov, William. 1972. Language in the Inner City: Studies in the Black English Vernacular. Philadelphia: University of Pennsylvania Press.

Meelberg, Vincent. 2006. New Sounds, New Stories: Narrativity in Contemporary Music. Leiden: Leiden University Press.

Prince, Gerald. 1982. Narratology: The Form and Functioning of Narrative. Berlin: Mouton.

Ranta, Michael. 2013. (Re-)creating order: Narrativity and implied world views in pictures. Storyworlds 5: 1-30.

Ryan, Marie-Laure. 2004a. Introduction. In Narrative across Media: The Languages of Storytelling, ed. Marie-Laure Ryan, 1-40. Lincoln and London: University of Nebraska Press.

. 2006. Avatars of Story. Minneapolis and London: University of Minnesota Press.

Smith, Murray. 2009. Double trouble: On film, fiction, and narrative. Storyworlds 1: 1-23. 
Smuts, Aaron. 2009. Story identity and story type. Journal of Aesthetics \& Art Criticism 67: 5-13.

Thon, Jan-Noël. 2016. Transmedial Narratology and Contemporary Media Culture. Lincoln and London: University of Nebraska Press.

Open Access This chapter is licensed under the terms of the Creative Commons Attribution 4.0 International License (http://creativecommons.org/licenses/ by $/ 4.0 /$ ), which permits use, sharing, adaptation, distribution and reproduction in any medium or format, as long as you give appropriate credit to the original author(s) and the source, provide a link to the Creative Commons licence and indicate if changes were made.

The images or other third party material in this chapter are included in the chapter's Creative Commons licence, unless indicated otherwise in a credit line to the material. If material is not included in the chapter's Creative Commons licence and your intended use is not permitted by statutory regulation or exceeds the permitted use, you will need to obtain permission directly from the copyright holder.

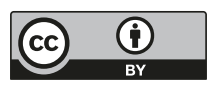

